From the National Cancer Institute, Rockville, MD.

Submitted November 8, 2009; accepted March 5, 2010; published online ahead of print at www.jco.org on April 26, 2010

Supported by the Intramural Research Program of the National Institutes of Health, National Cancer Institute.

Authors' disclosures of potential conflicts of interest and author contributions are found at the end of this article.

Corresponding author: Anil K. Chaturvedi, PhD, Infections and Immunoepidemiology Branch, Division of Cancer Epidemiology and Genetics, National Cancer Institute, National Institutes of Health, 6120 Executive Blvd, EPS 7072, Rockville, MD 20852; e-mail: chaturva@mail.nih.gov.

Published by the American Society of Clinical Oncology

0732-183X/10/2816-2719/\$20.00 DOI: 10.1200/JCO.2009.27.0454

\title{
C-Reactive Protein and Risk of Lung Cancer
}

Anil K. Chaturvedi, Neil E. Caporaso, Hormuzd A. Katki, Hui-Lee Wong, Nilanjan Chatterjee, Sharon R. Pine, Stephen J. Chanock, James J. Goedert, and Eric A. Engels

\section{$\begin{array}{llllllll}\text { A } & \text { B } & S & T & R & \text { A } & \text { C } & T\end{array}$}

\section{Purpose}

Chronic inflammation could play a role in lung carcinogenesis, underscoring the potential for lung cancer prevention and screening. We investigated the association of circulating high-sensitivity C-reactive protein (CRP, an inflammation biomarker) and CRP single nucleotide polymorphisms (SNPs) with prospective lung cancer risk.

\section{Patients and Methods}

We conducted a nested case-control study of 592 lung cancer patients and 670 controls with available prediagnostic serum and 378 patients and 447 controls with DNA within the screening arm of the Prostate, Lung, Colorectal, and Ovarian Cancer Screening Trial $(N=77,464)$. Controls were matched to patients on age, sex, entry year, follow-up time, and smoking. We measured CRP levels in baseline serum samples and genotyped five common CRP SNPs.

\section{Results}

Elevated CRP levels were associated with increased lung cancer risk lodds ratio [OR], 1.98; 95\% Cl, 1.35 to 2.89; P-trend $<.001$ for fourth quartile [Q4, $\geq 5.6 \mathrm{mg} / \mathrm{L}] \vee \mathrm{Q} 1[<1.0 \mathrm{mg} / \mathrm{L}])$. The CRP association did not differ significantly by histology, follow-up time, or smoking status, but was most apparent for squamous cell carcinomas (OR, 2.92; 95\% Cl, 1.30 to 6.54), 2 to 5 years before lung cancer diagnosis (OR, 2.33; 95\% Cl, 1.24 to 4.39), and among former smokers (OR, 2.48; $95 \% \mathrm{Cl}, 1.53$ to 4.03 ) and current smokers (OR, 1.90; $95 \% \mathrm{Cl}, 1.06$ to 3.41). Although CRP SNPs and haplotypes were associated with CRP levels, they were not associated with lung cancer risk. Ten-year standardized absolute risks of lung cancer were higher with elevated CRP levels among former smokers (Q4: $2.55 \% ; 95 \% \mathrm{Cl}, 1.98 \%$ to $3.27 \% \vee 01: 1.39 \% ; 95 \% \mathrm{Cl}, 1.07 \%$ to $1.81 \%$ ) and current smokers (Q4: 7.37\%; 95\% Cl, 5.81\% to $9.33 \% \vee$ Q1: $4.03 \%$; $95 \% \mathrm{Cl}, 3.01 \%$ to $5.40 \%$ ).

\section{Conclusion}

Elevated CRP levels are associated with subsequently increased lung cancer risk, suggesting an etiologic role for chronic pulmonary inflammation in lung carcinogenesis.

\section{J Clin Oncol 28:2719-2726. Published by the American Society of Clinical Oncology}

\section{INTRODUCTION}

Smoking is the major risk factor for lung cancer, the most common cancer worldwide. ${ }^{1}$ Nonetheless, smoking is neither necessary nor sufficient for lung cancer development, ${ }^{1}$ underscoring the influence of additional cofactors. Experimental as well as epidemiologic studies support a role for chronic pulmonary inflammation in lung carcinogenesis. ${ }^{2-4}$ Inflammatory lung conditions such as chronic obstructive pulmonary disease, ${ }^{5-8}$ elevated serum levels of pro-inflammatory cytokines, ${ }^{9-11}$ and polymorphisms in inflammation-related genes ${ }^{12-15}$ have all been linked with increased lung cancer risk.

Notably, elevated levels of C-reactive protein (CRP), a systemic marker of chronic inflammation, have been associated with increased lung cancer risk in several retrospective and a few pro-

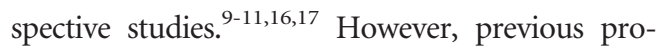
spective investigations have included only modest numbers of lung cancers (42 to 255 cases), thus precluding a precise estimation of risk overall and especially among subgroups defined by smoking status or lung cancer subtype. An alternative approach to evaluating the role of CRP in lung carcinogenesis is through investigating the relationship of lung cancer risk with CRP genetic polymorphisms, which are associated with variation in circulating CRP levels. ${ }^{11}$ Parallel assessments of both CRP genotypes and circulating CRP levels would help characterize the role of genetic versus environmental influences involved in CRP-related lung cancer risk. Only one previous study has evaluated lung cancer risk in relation to CRP genotypes. ${ }^{11}$

Understanding the role of chronic inflammation in lung cancer etiology could have relevance 
for prevention as well as screening of populations at high risk for lung cancer. This prospect is underscored by the utility of CRP measurement in cardiovascular disease risk stratification, where it is used to help target chemopreventive intervention (eg, with statin therapy). ${ }^{18-20}$ In the current nested case-control study within the Prostate, Lung, Colorectal, and Ovarian (PLCO) Cancer Screening Trial, we investigated the association of lung cancer with circulating prediagnostic CRP levels and CRP genotypes. We also calculated absolute risks of lung cancer across circulating CRP levels to evaluate the utility of this marker in lung cancer risk stratification.

\section{PATIENTS AND METHODS}

\section{Study Design}

The PLCO study, a randomized trial aimed at evaluating the efficacy of screening in reducing cancer mortality, recruited approximately 155,000 men and women age 55 to 74 years from 1992 to $2001 .^{21}$ Screening for lung cancer among participants in the intervention arm included a chest $\mathrm{x}$-ray at baseline followed by either three annual x-rays (for current or former smokers at enrollment) or two annual x-rays (for never smokers); participants in the control arm received routine health care. ${ }^{21}$ Screening-arm participants provided data on sociodemographic factors, smoking behavior, anthropometric characteristics, medical history, and family history of cancer, as well as blood samples annually for the first 6 years of the study (baseline [T0] and T1 through T5). ${ }^{22}$ Lung cancers were ascertained through annual questionnaires mailed to the participants, and positive reports were followed up by abstracting medical records or death certificates. Follow-up in the trial as of July 2009 was $96.7 \%$.

We conducted a nested case-control study within the screening arm of the PLCO trial. As of December 31, 2004, 898 lung cancers were diagnosed among the 77,464 participants. Patients were excluded because of missing baseline questionnaire, previous history of any cancer, diagnosis of multiple cancers during follow-up, missing smoking information at baseline, missing consent for utilization of biologic specimens for etiologic studies, or unavailability of serum or DNA specimens. Thus, we included 626 lung cancer patients in this case-control study.

Controls were individuals free of cancer at the time of a case's lung cancer diagnosis. Controls were individually matched to lung cancer patients on age at enrollment ( 55 to 59,60 to 64,65 to 69 , and 70 to 74 years), sex, year of random assignment, follow-up time since enrollment, and smoking status at enrollment (never, former, or current smoker). Current and former smokers were matched on cumulative amount of smoking ( 0 to 29,30 to 39,40 to 49 , and $50+$ pack-years $)$, with additional matching for time since quitting $(<15$ years and $\geq 15$ years) for former smokers. We matched never smoker controls to patients using a 3:1 ratio to enhance statistical power, whereas former and current smoker controls were matched to patients using a 1:1 ratio.

\section{Laboratory Methods}

High-sensitivity CRP was measured in baseline (T0) serum samples using a chemiluminescent immunoassay (Diagnostic Products Corporation, Los Angeles, CA). We assessed single nucleotide polymorphisms (SNPs) at five loci within the CRP gene (rs1417938, rs1800947, rs1205, rs2808630, and rs3093077) as part of a Golden Gate assay (Illumina, San Diego, CA). These SNPs were chosen on the basis of their high pair-wise linkage-disequilibrium (ie, tag SNPs with $r^{2}>80 \%$ ) with other common SNPs in the CRP region, spanning $20 \mathrm{~kb}$ upstream to $10 \mathrm{~kb}$ past the downstream polyA tail. The five SNPs tag five of eight bins in the CRP region. ${ }^{23}$ Four of the CRP SNPs (rs1417938, rs1800947, rs3093077, and rs1205) have been shown to be associated with differences in CRP levels. ${ }^{24,25}$ Of 399 patients and 467 controls with available DNA, genotyping was successful for 378 patients and 447 controls. We observed high reproducibility for serum CRP measurements across replicate samples ( $\mathrm{n}=90$ [six replicates each from 15 individuals]), with $93.3 \%$ concordance across CRP quartiles and an intraclass correlation coefficient of $99.4 \%$. Likewise, concordance was $100 \%$ for $C R P$ genotyping across 23 pairs of duplicates. Our analyses of circulating CRP levels included 592 patients and 670 controls, whereas the CRP SNP analyses included 378 patients and 447 controls. Data on both CRP levels and CRP genotypes were available for 345 patients and 402 controls.

\section{Statistical Analyses}

Data collected on the baseline questionnaire were used for all analyses. We used conditional logistic regression to estimate odds ratios (ORs) for the relationship of lung cancer risk with CRP levels. CRP levels were classified into quartiles on the basis of distribution among controls. Using the lowest quartile (Q1) as the reference, we assessed ORs for the second (Q2), third (Q3), and fourth (Q4) quartiles; we also treated the CRP quartiles as an ordinal variable to assess trends in risk. In addition to the matching variables, these models included adjustment for race/ethnicity, level of education, body mass index (BMI) at enrollment, regular use of aspirin/ibuprofen, family history of lung cancer, history of heart disease, and history of emphysema/bronchitis.

Associations of individual SNPs with lung cancer were evaluated using unconditional logistic regression, unadjusted and adjusted for the factors listed above. We inferred haplotype frequencies using the expectationmaximization algorithm ${ }^{26}$ and assessed associations with lung cancer using unconditional logistic regression.

We conducted separate analyses for never, former, and current smokers and across lung cancer histologies (adenocarcinoma $[\mathrm{AC}]$, squamous cell carcinoma [SCC], small-cell carcinoma, large-cell carcinoma, and other/unknown histologies). We also conducted analyses stratified by time interval between serum sampling and lung cancer diagnosis/control selection (ie, follow-up time, classified as $<1,1$ to 2,2 to 5 , and $\geq 5$ years).

We used linear regression to examine associations with CRP levels (logtransformed) among controls. These analyses considered questionnaire data and CRP genotypes and haplotypes as potential predictors.

We calculated standardized 10-year lung cancer absolute risks and risk differences across CRP quartiles among former and current smokers using a weighted Cox regression model. ${ }^{27,28}$ These absolute risk calculations were restricted to 58,220 screening-arm participants who were eligible for selection into our case-control study and were standardized to the screening-arm cohort's joint distribution of age, sex, year of random assignment, and smoking status (duration and intensity of smoking for current and former smokers, and time since quitting for former smokers). Additional details are presented in the Appendix (online only). All statistical tests were two-sided, and $P$ values $<.05$ were considered statistically significant.

\section{RESULTS}

Table 1 lists the characteristics of 592 patients and 670 controls with available serum and 378 patients and 447 controls with available DNA. By virtue of matching, patients and controls had similar distributions of age at enrollment, sex, and smoking behavior. For subjects with available serum, no significant differences were observed between patients and controls for race, BMI, regular use of aspirin/ ibuprofen, or history of heart disease. Compared with controls, patients more often had lower educational attainment $(P=.017)$, a personal history of bronchitis/emphysema $(P<.001)$, and a family history of lung cancer $(P=.004)$. Similar differences, albeit at a lower significance level, were observed among subjects with available DNA, and patients were significantly more likely to have a family history of lung cancer. All CRP SNPs conformed to the Hardy-Weinberg equilibrium among controls.

Individuals with CRP values in the highest quartile had a twofold increased risk of lung cancer when compared with individuals having CRP levels in the lowest quartile (OR, 1.98; 95\% CI, 1.35 to 2.89; Table 2), and a significant trend for increasing risk with increasing CRP levels was observed $(P$-trend $<.001)$. In contrast, none of the five $C R P$ SNPs was associated with lung cancer risk (Table 2). Of the 


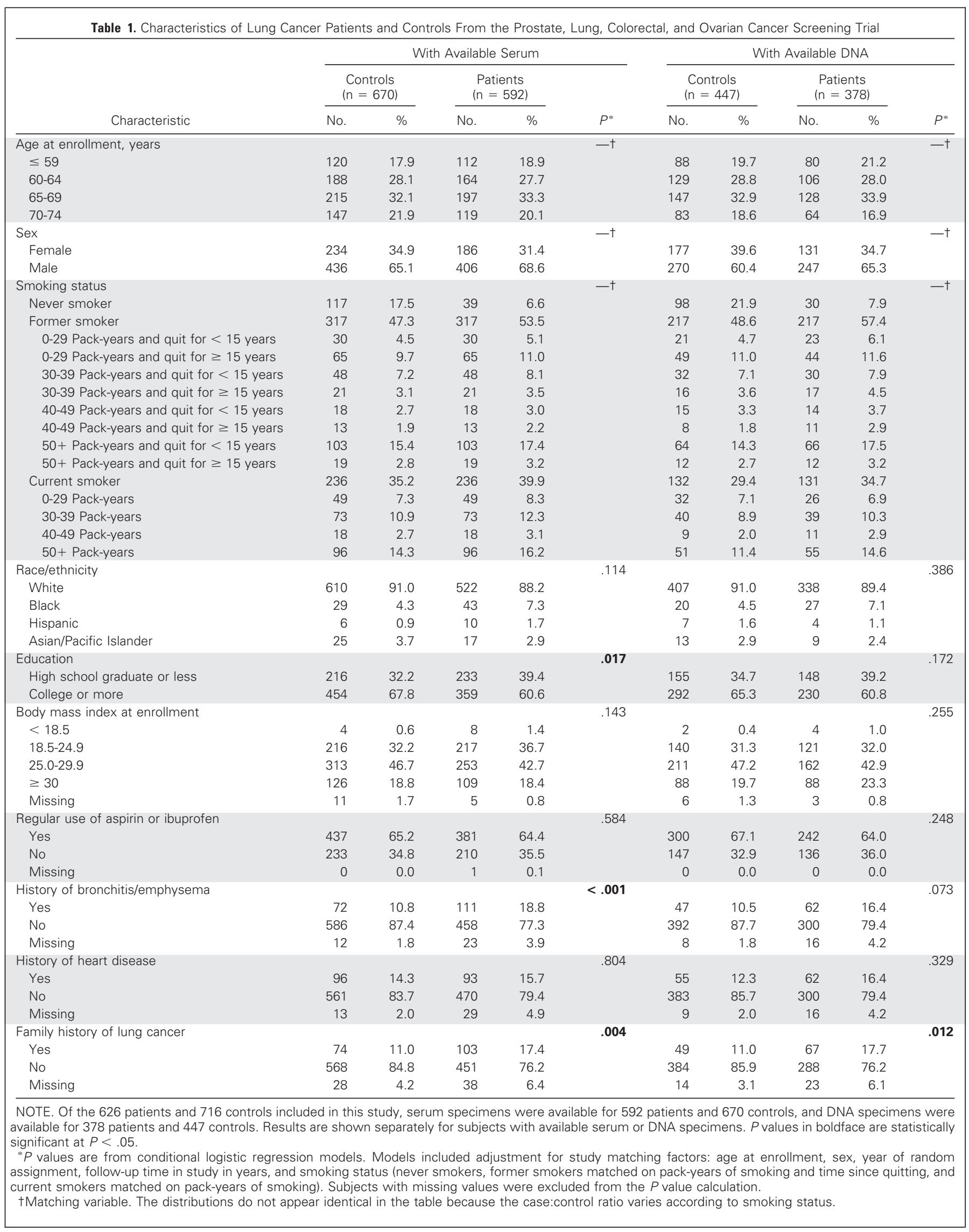




\begin{tabular}{|c|c|c|c|c|c|c|c|c|c|c|}
\hline \multirow[b]{2}{*}{ CRP Level and Genotype } & \multicolumn{2}{|c|}{ Controls* } & \multicolumn{2}{|c|}{ Patients* } & \multirow[b]{2}{*}{ OR } & \multirow[b]{2}{*}{$95 \% \mathrm{Cl}+$} & \multirow[b]{2}{*}{ P-Trend } & \multirow[b]{2}{*}{ Adjusted OR } & \multirow[b]{2}{*}{$95 \% \mathrm{Cl}$} & \multirow[b]{2}{*}{$P$-Trend } \\
\hline & No. & $\%$ & No. & $\%$ & & & & & & \\
\hline $\mathrm{CRP}, \mathrm{mg} / \mathrm{L}$ & & & & & & & $<.001$ & & & $<.001$ \\
\hline$\leq 1.0$ & 168 & 25.1 & 106 & 17.9 & 1.00 & & & 1.00 & & \\
\hline $1.1-2.7$ & 176 & 26.3 & 136 & 23.0 & 1.26 & 0.88 to 1.80 & & 1.22 & 0.83 to 1.78 & \\
\hline $2.8-5.5$ & 167 & 24.9 & 150 & 25.3 & 1.41 & 1.00 to 1.98 & & 1.54 & 1.08 to 2.21 & \\
\hline$\geq 5.6$ & 159 & 23.7 & 200 & 33.8 & 1.95 & 1.38 to 2.75 & & 1.98 & 1.35 to 2.89 & \\
\hline rs1417938 & & & & & & & .952 & & & .880 \\
\hline $\mathrm{AA}$ & 221 & 49.4 & 186 & 49.2 & 1.00 & & & 1.00 & & \\
\hline AT & 177 & 39.6 & 149 & 39.4 & 1.00 & 0.74 to 1.34 & & 1.04 & 0.76 to 1.42 & \\
\hline $\mathrm{TT}$ & 49 & 11.0 & 42 & 11.1 & 1.01 & 0.64 to 1.60 & & 1.00 & 0.62 to 1.63 & \\
\hline rs1800947 & & & & & & & .677 & & & .456 \\
\hline GG & 399 & 89.3 & 335 & 88.6 & 1.00 & & & 1.00 & & \\
\hline $\mathrm{CG}$ & 46 & 10.3 & 40 & 10.6 & 1.03 & 0.66 to 1.62 & & 1.16 & 0.72 to 1.88 & \\
\hline $\mathrm{CC}$ & 2 & 0.4 & 3 & 0.8 & 1.78 & 0.29 to 10.73 & & 1.50 & 0.22 to 9.94 & \\
\hline rs1205 & & & & & & & .960 & & & .667 \\
\hline $\mathrm{CC}$ & 204 & 45.7 & 167 & 44.2 & 1.00 & & & 1.00 & & \\
\hline $\mathrm{CT}$ & 188 & 42.2 & 168 & 44.8 & 1.09 & 0.81 to 1.46 & & 1.12 & 0.82 to 1.54 & \\
\hline $\mathrm{TT}$ & 54 & 12.1 & 40 & 10.7 & 0.90 & 0.57 to 1.42 & & 1.02 & 0.63 to 1.67 & \\
\hline rs2808630 & & & & & & & .527 & & & .652 \\
\hline $\mathrm{TT}$ & 242 & 54.1 & 206 & 54.5 & 1.00 & & & 1.00 & & \\
\hline $\mathrm{CT}$ & 172 & 38.5 & 153 & 40.5 & 1.04 & 0.78 to 1.39 & & 1.05 & 0.77 to 1.41 & \\
\hline $\mathrm{CC}$ & 33 & 7.4 & 19 & 5.0 & 0.67 & 0.37 to 1.22 & & 0.72 & 0.38 to 1.34 & \\
\hline rs3093077 & & & & & & & .813 & & & .570 \\
\hline $\mathrm{TT}$ & 375 & 83.9 & 316 & 83.6 & 1.00 & & & 1.00 & & \\
\hline GT & 70 & 15.7 & 59 & 15.6 & 1.00 & 0.68 to 1.45 & & 0.87 & 0.57 to 1.31 & \\
\hline GG & 2 & 0.4 & 3 & 0.8 & 1.77 & 0.29 to 10.69 & & 1.07 & 0.16 to 7.14 & \\
\hline \multicolumn{11}{|c|}{$\begin{array}{l}\text { NOTE. Values in boldface are statistically significant at } P<.05 \text {. Numbers do not add up to total owing to missing values. } \\
\text { Abbreviations: CRP, C-reactive protein; OR, odds ratio. } \\
\text { *Analyses for circulating CRP levels included } 592 \text { patients and } 670 \text { controls. Analyses for CRP genotypes included } 378 \text { patients and } 447 \text { controls. } \\
\text { tORs were calculated using conditional logistic regression (CRP levels) or unconditional logistic regression (CRP single nucleotide polymorphisms [SNPs]). ORs } \\
\text { for CRP levels were adjusted for matching factors: age at enrollment, sex, year of random assignment, follow-up time in study, and smoking status. ORs for CRP } \\
\text { SNPs were not adjusted for any factors. } \\
\text { fAdjusted ORs included adjustment for matching factors (CRP/SNP associations adjusted for age, sex, and smoking status) and additionally for race, level of education, } \\
\text { body mass index at enrollment, regular use of aspirin/ibuprofen, family history of lung cancer, history of heart disease, and history of emphysema/bronchitis. }\end{array}$} \\
\hline
\end{tabular}

five CRP SNPs, four SNPs formed haplotype blocks, and these haplotypes were also unrelated to lung cancer (Appendix Table A1, online only).

In analyses stratified by histology (Fig 1A), elevated CRP levels (Q3 and Q4) were associated with increased risk of SCC lung cancers (eg, Q4 v Q1: OR, 2.92; 95\% CI, 1.30 to 6.54; $P$-trend $=.008$ ), but not lung ACs (Q4 v Q1: OR, 1.34; 95\% CI, 0.83 to 2.17; P-trend = .172). Elevated CRP levels were also associated with increased risk of small-cell carcinomas (Q4 $v$ Q1: OR, 3.03; 95\% CI, 1.04 to 8.83; Ptrend $=.040)$. However, this difference across subtypes was not statistically significant $(P$ value for difference in slopes $=.361)$. The mean time between serum sampling and subject selection was 3.36 years (standard deviation, 2.59). The relationship of CRP with lung cancer did not vary significantly by follow-up time (Fig $1 \mathrm{~B}$; Pinteraction $=.581$ ), although the association appeared strongest in the period 2 to 5 years before lung cancer diagnosis (Q $4 v \mathrm{Q} 1: \mathrm{OR}, 2.33$; 95\% CI, 1.24 to 4.39 ).

Elevated CRP levels were associated with increased lung cancer risk among former smokers (Fig 1C; Q4 $v$ Q1: OR, 2.48; 95\% CI, 1.53 to $4.03 ; P$-trend $=.001)$ and current smokers $(\mathrm{Q} 4 v \mathrm{Q} 1: \mathrm{OR}, 1.90 ; 95 \%$ CI, 1.06 to $3.41 ; P$-trend $=.019$ ), but not among never smokers. However, the difference across smoking strata was not statistically significant $(P$-interaction $=.589)$. For former smokers, elevated CRP levels were associated with increased lung cancer risk among individuals who quit smoking for $<15$ years (Q4 $v$ Q1: OR, 2.70; 95\% CI, 1.47 to 4.95 ) as well as among those who quit for $>15$ years (OR, 2.17; $95 \%$ CI, 0.94 to 5.01$)$.

Among controls (Table 3), CRP levels varied significantly by age and were higher among current smokers, Hispanics, individuals with a high BMI, and among individuals with a family history of lung cancer. CRP levels increased with cumulative amount of smoking and smoking intensity but were unrelated to time since quitting among former smokers.

CRP levels were significantly associated with CRP SNPs rs1800947 (decreased levels for CC or CG $v$ GG genotype; $P$-trend $=.016$ ), rs1205 (decreased levels for TT or CT $v$ CC genotype; $P$-trend $=.008$ ), and rs3093077 (increased levels for GG or GT $v$ TT genotype; $P$-trend $=.003$; Table 3). Likewise, CRP levels differed across haplotypes formed by four SNPs: rs1417938, rs1800947, rs1205, and rs2808630 (Appendix Table A1). Compared with the most common haplotype (TGCT), haplotypes AGTT and ACTT were associated with lower CRP levels, whereas haplotype AGCT was associated with higher CRP levels. The individual CRP SNPs rs1417938, rs1800947, rs1205, rs2808630, and rs3093077 accounted for 0.5\%, 1.4\%, 2.5\%, $0.4 \%$, and $2.6 \%$, respectively, of the total variability in circulating CRP levels (Appendix Table A2, online only). 
A

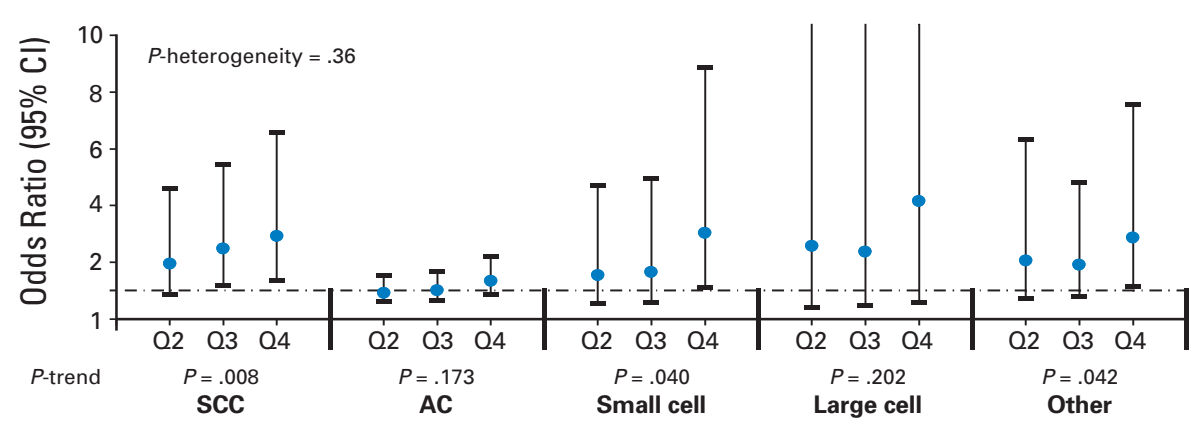

B

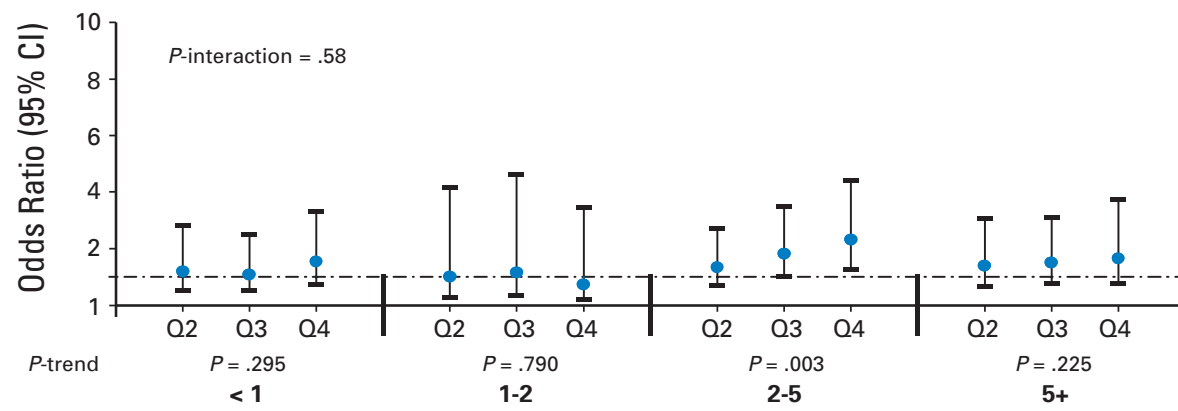

C

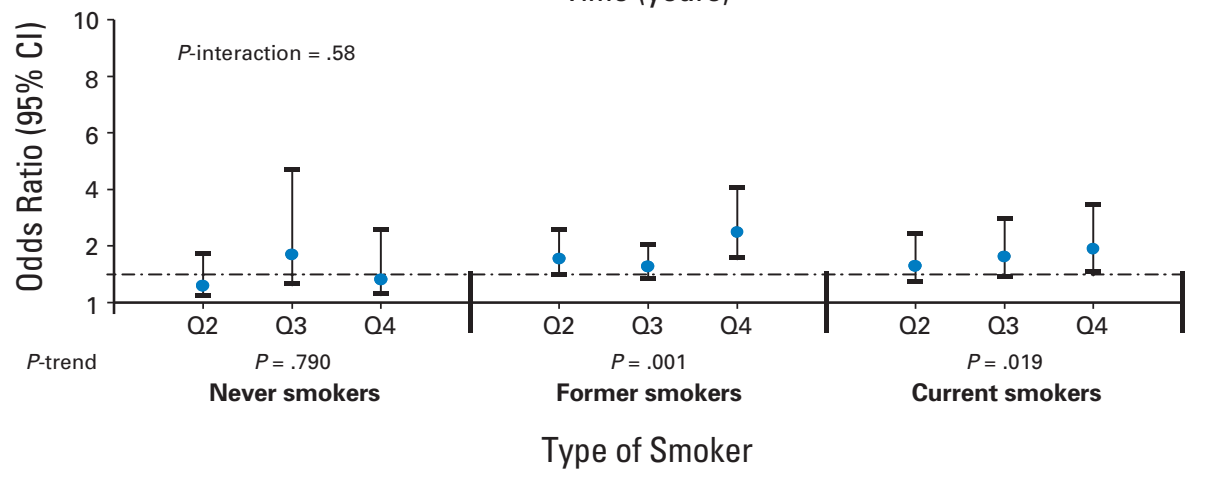

Fig 1. Association of circulating C-reactive protein (CRP) levels with lung cancer risk across (A) lung cancer histologies (squamous cell carcinomas [SCCs; $n=126$ lung cancers], adenocarcinomas [ACs; $n=269$ ], small-cell carcinomas [ $\mathrm{n}=75$ ], large-cell carcinomas [ $n=36$ ], and cancers of other/ unknown histologies [ $n=86]$ ), (B) follow-up time $(<1$ year [ $n=128$ lung cancers], 1 to 2 years [ $n=70], 2$ to 5 years [ $n=238$ ], and $5+$ years $[n=156])$, and (C) smoking strata (never smokers [ $\mathrm{n}=39$ lung cancers], former smokers [n = 318], and current smokers [ $\mathrm{n}=236]$ ). Odds ratios (ORs) and 95\% Cls were estimated in conditional logistic regression models, and by virtue of matching, incorporated adjustment for age, sex, year of random assignment, follow-up time, and smoking (see Patients and Methods for details). ORs and $95 \% \mathrm{Cls}$ are shown for the second (Q2), third (Q3), and fourth (Q4) quartiles compared with the first quartile (Q1). P-trend values for ORs across CRP quartiles are shown. P-heterogeneity values are shown for the association of CRP quartiles (treated as an ordinal variable with $1 d f$ ) with risk of specific lung cancer histologic subsites (A), as well as for the multiplicative statistical interaction between CRP levels and follow-up time (B) and cigarette smoking $(\mathrm{C})$ on lung cancer risk.
Standardized absolute risks of lung cancer over 10 years of follow-up across CRP quartiles among former and current smokers are shown in Table 4. For former smokers, the 10-year absolute risk was $2.55 \%$ (95\% CI, $1.98 \%$ to $3.27 \%$ ) among individuals with CRP levels $\geq 5.6 \mathrm{mg} / \mathrm{L}$ versus $1.39 \%$ (95\% CI, $1.07 \%$ to $1.81 \%$ ) among those with CRP levels of $<1.0 \mathrm{mg} / \mathrm{L}$ (risk difference, $1.15 \%$; $95 \% \mathrm{CI}$, $0.41 \%$ to $1.89 \%$ ). For current smokers, the 10 -year absolute risk was much higher among individuals with CRP levels $\geq 5.6 \mathrm{mg} / \mathrm{L} \mathrm{com-}$ pared with those with CRP levels of $<1.0 \mathrm{mg} / \mathrm{L}$ (absolute risk, 7.37\%; $95 \% \mathrm{CI}, 5.81 \%$ to $9.33 \% \vee 4.03 \%$; $95 \% \mathrm{CI}, 3.01 \%$ to $5.40 \%$; risk difference, $3.33 \%$; $95 \% \mathrm{CI}, 1.24 \%$ to $5.42 \%$ ).

\section{DISCUSSION}

This study is the largest to date to evaluate the association of serum CRP levels and CRP genotypes with prospective lung cancer risk. Elevated CRP levels were associated with increased lung cancer risk, and risk rose steadily with increasing CRP levels. Likewise, we ob- served clear separation in 10-year lung cancer absolute risks across CRP quartiles among former and current smokers. In contrast, although significantly associated with differences in CRP levels, SNPs in the CRP gene were not related to lung cancer risk.

Our observations that elevated CRP levels were associated with a two-fold increased risk of lung cancer are consistent with previous smaller prospective studies. ${ }^{9-11,17}$ Because we tightly controlled for smoking through matching, it is unlikely that the CRP associations are explained entirely by smoking. Notably, CRP levels were also elevated among former smokers and were associated with increased lung cancer risk even among those who had quit smoking for up to 15 years. Nonetheless, cigarette smoke itself can lead to pulmonary inflammation, ${ }^{4,29}$ and we found high CRP levels among current smokers in relation to the amount smoked. It is possible that, despite similar tobacco exposures, elevated CRP levels may identify those individuals with a heightened inflammatory response to tobacco smoke and thus at highest lung cancer risk. 


\begin{tabular}{|c|c|c|c|}
\hline Characteristic & $\begin{array}{l}\text { No. of } \\
\text { Patients }\end{array}$ & $\begin{array}{c}\text { Geometric } \\
\text { Mean } \\
\text { CRP Level } \\
\text { (mg/L) }\end{array}$ & $P^{*}$ \\
\hline \multicolumn{3}{|l|}{ Age at enrollment, years } & .013 \\
\hline$\leq 59$ & 120 & 1.94 & \\
\hline $60-64$ & 186 & 2.08 & \\
\hline $65-69$ & 208 & 2.65 & \\
\hline $70-74$ & 144 & 1.92 & \\
\hline \multicolumn{3}{|l|}{ Sex } & .217 \\
\hline Female & 233 & 2.25 & \\
\hline Male & 425 & 2.01 & \\
\hline \multicolumn{3}{|l|}{ Smoking status } & .023 \\
\hline Never smoker & 116 & 1.80 & \\
\hline Former smoker & 312 & 2.12 & \\
\hline Current smoker & 230 & 2.53 & \\
\hline \multicolumn{3}{|l|}{ Former smoker } & .012 \\
\hline \multicolumn{3}{|l|}{$\begin{array}{l}0-29 \text { Pack-years and quit for } \\
<15 \text { years }\end{array}$} & \\
\hline \multicolumn{3}{|l|}{$\begin{array}{l}0-29 \text { Pack-years and quit for } \\
\geq 15 \text { years }\end{array}$} & \\
\hline \multicolumn{4}{|l|}{$\begin{array}{l}\text { 30-39 Pack-years and quit for } \\
<15 \text { years }\end{array}$} \\
\hline \multicolumn{4}{|l|}{$\begin{array}{l}\text { 30-39 Pack-years and quit for } \\
\geq 15 \text { years }\end{array}$} \\
\hline \multicolumn{4}{|l|}{$\begin{array}{l}\text { 40-49 Pack-years and quit for } \\
<15 \text { years }\end{array}$} \\
\hline \multicolumn{4}{|l|}{$\begin{array}{l}\text { 40-49 Pack-years and quit for } \\
\geq 15 \text { years }\end{array}$} \\
\hline \multicolumn{4}{|l|}{$\begin{array}{l}50+\text { Pack-years and quit for } \\
<15 \text { years }\end{array}$} \\
\hline $\begin{array}{l}50+\text { Pack-years and quit for } \\
\quad \geq 15 \text { years }\end{array}$ & 19 & 3.07 & \\
\hline \multicolumn{3}{|l|}{ Current smoker } & .011 \\
\hline 0-29 Pack-years & 47 & 2.30 & \\
\hline 30-39 Pack-years & 71 & 2.08 & \\
\hline 40-49 Pack-years & 17 & 4.08 & \\
\hline $50+$ Pack-years & 95 & 3.28 & \\
\hline \multicolumn{4}{|l|}{$\begin{array}{l}\text { Current smokers by smoking } \\
\text { intensity, cigarettes per day }\end{array}$} \\
\hline$\leq 10$ & 35 & 2.17 & .023 \\
\hline $11-20$ & 88 & 2.44 & \\
\hline $21-40$ & 94 & 3.30 & \\
\hline $40+$ & 13 & 4.80 & \\
\hline \multicolumn{3}{|l|}{ Race/ethnicity } & .006 \\
\hline White & 599 & 2.40 & \\
\hline Black & 29 & 2.64 & \\
\hline Hispanic & 6 & 2.89 & \\
\hline Asian/Pacific Islander & 24 & 1.12 & \\
\hline \multicolumn{3}{|l|}{ Education } & .172 \\
\hline High school graduate or less & 212 & 2.26 & \\
\hline College or more & 446 & 2.00 & \\
\hline \multicolumn{3}{|l|}{ BMI at enrollment } & $<.001$ \\
\hline$<18.5$ & 4 & 1.33 & \\
\hline $18.5-24.9$ & 214 & 1.45 & \\
\hline $25.0-29.9$ & 305 & 2.24 & \\
\hline$\geq 30$ & 124 & 3.31 & \\
\hline \multicolumn{3}{|l|}{$\begin{array}{l}\text { Regular use of aspirin or } \\
\text { ibuprofen }\end{array}$} & .262 \\
\hline No & 230 & 2.00 & \\
\hline Yes & 428 & 2.21 & \\
\hline \multicolumn{4}{|c|}{ (continued in next column) } \\
\hline
\end{tabular}

\begin{tabular}{|c|c|c|c|}
\hline Characteristic & $\begin{array}{c}\text { No. of } \\
\text { Patients }\end{array}$ & $\begin{array}{c}\text { Geometric } \\
\text { Mean } \\
\text { CRP Level } \\
\text { (mg/L) }\end{array}$ & $P^{*}$ \\
\hline History of bronchitis/emphysema & & & .157 \\
\hline No & 574 & 2.07 & \\
\hline Yes & 72 & 2.50 & \\
\hline History of heart disease & & & .087 \\
\hline No & 551 & 2.08 & \\
\hline Yes & 94 & 2.56 & \\
\hline Family history of lung cancer & & & .004 \\
\hline No & 558 & 2.08 & \\
\hline Yes & 72 & 3.05 & \\
\hline rs1417938 & & & $.138 \dagger$ \\
\hline AA & 200 & 2.19 & \\
\hline AT & 158 & 2.53 & \\
\hline $\mathrm{TT}$ & 44 & 2.66 & \\
\hline rs1800947 & & & $.016 \dagger$ \\
\hline GG & 359 & 2.47 & \\
\hline CG & 42 & 1.71 & \\
\hline $\mathrm{CC}$ & 1 & 0.69 & \\
\hline rs1205 & & & $.008 \dagger$ \\
\hline $\mathrm{CC}$ & 186 & 2.57 & \\
\hline $\mathrm{CT}$ & 167 & 2.44 & \\
\hline $\mathrm{TT}$ & 48 & 1.51 & \\
\hline rs2808630 & & & $.451 \dagger$ \\
\hline TT & 218 & 2.39 & \\
\hline CT & 151 & 2.45 & \\
\hline $\mathrm{CC}$ & 33 & 1.87 & \\
\hline rs3093077 & & & $.003 \dagger$ \\
\hline $\mathrm{TT}$ & 337 & 2.23 & \\
\hline GT & 63 & 3.10 & \\
\hline GG & 2 & 13.20 & \\
\hline \multicolumn{4}{|c|}{$\begin{array}{l}\text { NOTE. Serum specimens were available for } 658 \text { controls, DNA specimens } \\
\text { were available for } 447 \text { controls, and both serum and DNA specimens wer } \\
\text { available for } 402 \text { controls. The number of controls with available serum is } \\
\text { different from that in Table } 1 \text { owing to the exclusion of instances of multiple } \\
\text { selections for controls who were selected more than once (n }=12 \text { controls; } \\
10 \text { controls selected two times, and one control selected three times) owing } \\
\text { to sampling with replacement. } P \text { values in boldface are statistically significant } \\
\text { at } P<.05 \text {. Numbers do not add up to total owing to missing values. } \\
\text { Abbreviations: CRP, C-reactive protein; BMl, body mass index. } \\
{ }^{*} P \text { values from linear regression models that incorporated age, sex, race, } \\
\text { and smoking. } \\
+P \text { values for trend across categories; not adjusted for any factors. }\end{array}$} \\
\hline
\end{tabular}

In addition to smoking, several factors could lead to chronic pulmonary inflammation, including chronic lung infections with microorganisms such as mycobacteria or Chlamydia pneumoniae; particulate matter such as asbestos or silica; and lung conditions such as asthma, idiopathic pulmonary fibrosis, and pulmonary scarring. ${ }^{4}$ Indeed, all of these factors have been associated with increased lung cancer risk. ${ }^{4,30,31} \mathrm{~A}$ chronic inflammatory response to these insults could result in increased cellular turnover and accumulation of reactive oxygen species which, in turn, could act as promoters to amplify the mutagenic effects of cigarette smoke. ${ }^{32}$

One limitation is that, although serum CRP levels reliably indicate the presence of chronic inflammation, CRP is not a specific marker for inflammation in the lung. While elevated CRP levels to some extent could arise from nonpulmonary inflammatory conditions, we nonetheless observed nonsignificantly elevated CRP levels 


\begin{tabular}{|c|c|c|c|c|}
\hline $\begin{array}{l}\text { CRP Levels } \\
\text { (mg/L) }\end{array}$ & $\begin{array}{l}\text { Absolute } \\
\text { Risk (\%) }\end{array}$ & $95 \% \mathrm{Cl}$ & $\begin{array}{l}\text { Standardized } \\
\text { Absolute Risk } \\
\text { Difference (\%) }\end{array}$ & $95 \% \mathrm{Cl}$ \\
\hline \multicolumn{5}{|c|}{ Former smokers } \\
\hline$\leq 1.0$ & 1.39 & 1.07 to 1.81 & Reference & \\
\hline $1.1-2.7$ & 1.79 & 1.38 to 2.31 & 0.39 & -0.17 to 0.96 \\
\hline $2.8-5.5$ & 1.94 & 1.52 to 2.49 & 0.55 & -0.06 to 1.16 \\
\hline$\geq 5.6$ & 2.55 & 1.98 to 3.27 & 1.15 & 0.41 to 1.89 \\
\hline \multicolumn{5}{|c|}{ Current smokers } \\
\hline$\leq 1.0$ & 4.03 & 3.01 to 5.40 & Reference & \\
\hline $1.1-2.7$ & 5.18 & 3.92 to 6.83 & 1.14 & -0.51 to 2.79 \\
\hline $2.8-5.5$ & 5.64 & 4.39 to 7.22 & 1.60 & -0.17 to 3.37 \\
\hline$\geq 5.6$ & 7.37 & 5.81 to 9.33 & 3.33 & 1.24 to 5.42 \\
\hline
\end{tabular}

NOTE. Absolute risks were standardized to the distributions of the following variables in the Prostate, Lung, Colorectal, and Ovarian (PLCO) Cancer Screening Trial's screening-arm cohort: age, sex, year of random assignment, smoking duration and intensity, and time since quitting (for former smokers). Abbreviation: CRP, C-reactive protein.

among individuals with a history of bronchitis or emphysema. Furthermore, elevated systemic CRP levels have been shown to be associated with incident chronic obstructive pulmonary disease $\mathrm{e}^{33,34}$ as well as progression of dysplastic lung lesions, ${ }^{35}$ indicating that systemic CRP levels can partly reflect aspects of pulmonary inflammation that are relevant in lung carcinogenesis.

Consistent with previous studies, ${ }^{11,17}$ elevated CRP levels were significantly associated with risk of lung SCCs and small-cell cancers but not ACs, although this difference across lung cancer subtypes was not statistically significant. Notably, the number of lung ACs in our study was higher than lung SCCs, arguing against differences in statistical power as a potential explanation for the null association with ACs. The reasons for these differential associations of CRP levels across lung cancer histologies are unclear and warrant further investigation.

Although CRP genotypes were associated with systemic CRP levels, little of the variation in CRP levels was explained by CRP SNPs, and we found that $C R P$ genotypes did not predict lung cancer risk. These observations contrast with results from a previous study showing a significant association of CRP SNP rs1205 with increased lung cancer risk. ${ }^{11}$ Nonetheless, the absence of an association of CRP SNPs with lung cancer risk parallels recent observations for cardiovascular disease. $^{24,25,36}$ Our data suggest that circulating CRP levels are determined by both genetic and environmental factors. ${ }^{24}$ The lack of association between CRP genotypes and lung cancer highlights the predominance of environmental factors in determining CRP-related lung cancer risk. Nevertheless, we note that our results do not discount the possibility that variations in other genes could modulate chronic inflammation in ways relevant for lung cancer.

Given the accruing evidence for a significant association of circulating CRP levels with lung cancer, we calculated standardized absolute risks of lung cancer as a preliminary approach to evaluating the utility of CRP in lung cancer risk stratification. The discrimination in absolute risks that we observed indicates that CRP measurements may aid in identifying former and current smokers at highest lung cancer risk. It remains to be seen whether the addition of CRP to lung cancer risk prediction models, which currently include standard risk factors such as age, sex, and smoking behaviors, ${ }^{37-39}$ would afford improvements in risk prediction, akin to recent observations for cardiovascular disease. ${ }^{18-20}$ Additionally, differential associations across lung cancer histologies will have to be considered in risk prediction.

The strengths of our study include the assessment of CRP genotypes and circulating CRP levels in conjunction, highly standardized procedures for data collection and disease ascertainment, and careful control for a range of potential confounding factors. Furthermore, although reverse causality cannot be ruled out, it is unlikely, given the use of prediagnostic specimens, our observation that CRP levels were elevated up to 5 years before lung cancer diagnosis, and the aggressive clinical course of most lung cancers. We also note the limitations of our study. We used systemic CRP level as a marker of pulmonary inflammation, but elevated CRP levels can arise from several nonpulmonary processes. Additional studies are needed to investigate the correlation of systemic inflammatory markers such as CRP with local lung inflammation. Similarly, the process of inflammation encompasses several pathways, and a more comprehensive evaluation of inflammatory markers is required to further characterize the role of chronic inflammation in lung carcinogenesis. Despite the large number of lung cancers in our study, some subgroup analyses were based on small numbers and should therefore be interpreted with caution. Finally, because our absolute risk estimates do not account for competing mortality, these values do not represent the observed proportion of individuals developing lung cancer.

In conclusion, we found that elevated CRP levels were associated with significantly increased risk of lung cancer, suggesting an etiologic role for chronic inflammation in lung carcinogenesis. Our key observation was that elevated CRP levels preceded lung cancer diagnosis by several years. The separation in lung cancer absolute risks across circulating CRP levels among former and current smokers provides preliminary evidence for the utility of CRP measurements in lung cancer risk stratification. These results also highlight the possibility that interventions targeting pulmonary inflammation may be effective in reducing lung cancer risk.

\section{AUTHORS' DISCLOSURES OF POTENTIAL CONFLICTS OF INTEREST}

The author(s) indicated no potential conflicts of interest.

\section{AUTHOR CONTRIBUTIONS}

Conception and design: Anil K. Chaturvedi, Neil E. Caporaso, Nilanjan Chatterjee, Stephen J. Chanock, James J. Goedert, Eric A. Engels Financial support: Anil K. Chaturvedi, Eric A. Engels Administrative support: Anil K. Chaturvedi, Eric A. Engels Provision of study materials or patients: Anil K. Chaturvedi, Eric A. Engels

Collection and assembly of data: Anil K. Chaturvedi, Eric A. Engels Data analysis and interpretation: Anil K. Chaturvedi, Neil E. Caporaso, Hormuzd A. Katki, Hui-Lee Wong, Nilanjan Chatterjee, Sharon R. Pine, Stephen J. Chanock, James J. Goedert, Eric A. Engels

Manuscript writing: Anil K. Chaturvedi, Neil E. Caporaso, Hormuzd A. Katki, Hui-Lee Wong, Nilanjan Chatterjee, Sharon R. Pine, Stephen J. Chanock, James J. Goedert, Eric A. Engels

Final approval of manuscript: Anil K. Chaturvedi, Neil E. Caporaso, Hormuzd A. Katki, Hui-Lee Wong, Nilanjan Chatterjee, Sharon R. Pine, Stephen J. Chanock, James J. Goedert, Eric A. Engels 


\section{REFERENCES}

1. Alberg AJ, Brock MV, Samet JM: Epidemiology of lung cancer: Looking to the future. J Clin Oncol 23:3175-3185, 2005

2. Bauer AK, Dwyer-Nield LD, Keil K, et al: Butylated hydroxytoluene (BHT) induction of pulmonary inflammation: A role in tumor promotion. Exp Lung Res 27:197-216, 2001

3. Ballaz S, Mulshine JL: The potential contributions of chronic inflammation to lung carcinogenesis. Clin Lung Cancer 5:46-62, 2003

4. Engels EA: Inflammation in the development of lung cancer: Epidemiological evidence. Expert Rev Anticancer Ther 8:605-615, 2008

5. Santillan AA, Camargo CA Jr, Colditz GA: A meta-analysis of asthma and risk of lung cancer (United States). Cancer Causes Control 14:327-334. 2003

6. Sin DD, Man SF: Impact of cancers and cardiovascular diseases in chronic obstructive pulmonary disease. Curr Opin Pulm Med 14:115-121, 2008

7. Purdue MP, Gold L, Jarvholm B, et al: Impaired lung function and lung cancer incidence in a cohort of Swedish construction workers. Thorax 62:51-56, 2007

8. Brody JS, Spira A: State of the art: Chronic obstructive pulmonary disease, inflammation, and lung cancer. Proc Am Thorac Soc 3:535-537, 2006

9. II'yasova D, Colbert LH, Harris $T B$, et al: Circulating levels of inflammatory markers and cancer risk in the health aging and body composition cohort. Cancer Epidemiol Biomarkers Prev 14:24132418, 2005

10. Trichopoulos $D$, Psaltopoulou $T$, Orfanos $P$, et al: Plasma C-reactive protein and risk of cancer: $\mathrm{A}$ prospective study from Greece. Cancer Epidemiol Biomarkers Prev 15:381-384, 2006

11. Siemes C, Visser LE, Coebergh JW, et al: C-reactive protein levels, variation in the C-reactive protein gene, and cancer risk: The Rotterdam Study. $\mathrm{J}$ Clin Oncol 24:5216-5222, 2006

12. Engels EA, Wu X, Gu J, et al: Systematic evaluation of genetic variants in the inflammation pathway and risk of lung cancer. Cancer Res 67: 6520-6527, 2007

13. Campa D, Zienolddiny $S$, Maggini $V$, et al: Association of a common polymorphism in the cy- clooxygenase 2 gene with risk of non-small cell lung cancer. Carcinogenesis 25:229-235, 2004

14. Shih CM, Lee YL, Chiou HL, et al: The involvement of genetic polymorphism of IL-10 promoter in non-small cell lung cancer. Lung Cancer 50:291-297, 2005

15. Seifart C, Plagens A, Dempfle A, et al: TNFalpha, TNF-beta, IL-6, and IL-10 polymorphisms in patients with lung cancer. Dis Markers 21:157-165, 2005

16. Heikkilä K, Ebrahim S, Lawlor DA: A systematic review of the association between circulating concentrations of $\mathrm{C}$ reactive protein and cancer J Epidemiol Community Health 61:824-833, 2007

17. Allin $\mathrm{KH}$, Bojesen SE, Nordestgaard BG: Baseline $\mathrm{C}$-reactive protein is associated with incident cancer and survival in patients with cancer. J Clin Oncol 27:2217-2224, 2009

18. Verma S, Szmitko PE, Ridker PM: C-reactive protein comes of age. Nat Clin Pract Cardiovasc Med 2:29-36, 2005

19. Ridker PM, Paynter NP, Rifai $N$, et al: $\mathrm{C}$-reactive protein and parental history improve global cardiovascular risk prediction: The Reynolds Risk Score for men. Circulation 118:2243-2251, 2008

20. Ridker PM, Buring JE, Rifai N, et al: Development and validation of improved algorithms for the assessment of global cardiovascular risk in women: The Reynolds Risk Score. JAMA 297:611-619, 2007

21. Prorok PC, Andriole GL, Bresalier RS, et al: Design of the Prostate, Lung, Colorectal and Ovarian (PLCO) Cancer Screening Trial. Control Clin Trials 21:273S-309S, 2000 (suppl 6)

22. Hayes RB, Sigurdson A, Moore L, et al: Methods for etiologic and early marker investigations in the PLCO trial. Mutat Res 592:147-154, 2005

23. Carlson CS, Eberle MA, Rieder MJ, et al: Selecting a maximally informative set of singlenucleotide polymorphisms for association analyses using linkage disequilibrium. Am J Hum Genet 74: 106-120, 2004

24. Danik JS, Ridker PM: Genetic determinants of C-reactive protein. Curr Atheroscler Rep 9:195-203, 2007

25. Zacho J, Tybjaerg-Hansen A, Jensen JS, et al: Genetically elevated C-reactive protein and ischemic vascular disease. N Engl J Med 359:1897-1908, 2008
26. Gabriel SB, Schaffner SF, Nguyen $H$, et al: The structure of haplotype blocks in the human genome. Science 296:2225-2229, 2002

27. Mark SD, Katki HA: Specifying and implementing nonparametric and semiparametric survival estimators in two-stage (sampled) cohort studies with missing case data. J Am Stat Assoc 101:460471, 2006

28. Katki HA, Mark SD: Survival analysis for cohorts with missing covariate information. $\mathrm{R}$ News 8:14-19, 2008

29. Peebles KA, Lee JM, Mao JT, et al: Inflammation and lung carcinogenesis: Applying findings in prevention and treatment. Expert Rev Anticancer Ther 7:1405-1421, 2007

30. Littman AJ, Jackson LA, Vaughan TL: Chlamydia pneumoniae and lung cancer: Epidemiologic evidence. Cancer Epidemiol Biomarkers Prev 14: 773-778, 2005

31. Yu YY, Pinsky PF, Caporaso NE, et al: Lung cancer risk following detection of pulmonary scarring by chest radiography in the prostate, lung, colorectal, and ovarian cancer screening trial. Arch Intern Med 168:2326-2332, 2008

32. Coussens LM, Werb Z: Inflammation and cancer. Nature 420:860-867, 2002

33. Gan WO, Man SF, Senthilselvan A, et al: Association between chronic obstructive pulmonary disease and systemic inflammation: A systematic review and a meta-analysis. Thorax 59:574-580 2004

34. van Durme YM, Verhamme KM, Aarnoudse AJ et al: $\mathrm{C}$-reactive protein levels, haplotypes, and the risk of incident chronic obstructive pulmonary disease. Am J Respir Crit Care Med 179:375-382, 2009

35. Sin DD, Man SF, McWilliams A, et al: Progression of airway dysplasia and C-reactive protein in smokers at high risk of lung cancer. Am J Respir Crit Care Med 173:535-539, 2006

36. Schunkert H, Samani NJ: Elevated C-reactive protein in atherosclerosis: Chicken or egg? $\mathrm{N}$ Eng J Med 359:1953-1955, 2008

37. Bach PB, Kattan MW, Thornquist MD, et al: Variations in lung cancer risk among smokers. J Nat Cancer Inst 95:470-478, 2003

38. Spitz MR, Hong WK, Amos $\mathrm{Cl}$, et al: A risk model for prediction of lung cancer. J Natl Cancer Inst 99:715-726, 2007

39. Cassidy A, Duffy SW, Myles JP, et al: Lung cancer risk prediction: A tool for early detection. Int J Cancer 120:1-6, 2007 